\title{
DERECHOS LINGÜÍSTICOS DE LAS COMUNIDADES CAMPESINAS ANDINAS Y EL SISTEMA REGISTRAL PERUANO
}

\section{LINGUISTIC RIGHTS OF THE ANDEAN PEASANT COMMUNITIES AND THE PERUVIAN REGISTRY SYSTEM}

\author{
CHAKRA RUNAKUNAPA SIMINKUNA HAYÑIN, SISTEMA \\ REGISTRAL PERUANO, IMA ${ }^{(1)}$
}

\author{
Ericson Delgado Otazu(2) \\ Ruby Milena Zans Delgado(3) \\ Universidad Andina del Cusco
}

\begin{abstract}
Resumen: Las Comunidades campesinas son organizaciones sociales tradicionales con existencia en el Perú desde tiempos ancestrales, cuentan con derechos individuales y colectivos reconocidos tanto en la esfera internacional como a nivel nacional, para protegerlas. El Estado tiene la obligación de generar y administrar un registro, a cargo de la Superintendencia Nacional de los Registros Públicos, para su reconocimiento legal, protección y desarrollo de sus derechos, pero hay ciertos aspectos no contemplados en el ordenamiento legal, así como una mala práctica en el sistema registral peruano, que vulnera los derechos comunales, entre otros los relacionados a los derechos lingüísticos, que colisionan con las normas internacionales reconocidas por el Estado, lo cual genera una desprotección y la necesidad de implementar una adecuada política pública.
\end{abstract}

Palabras claves: Derechos lingüísticos, comunidades campesinas, sistema registral.

Abstract: Peasant communities are traditional social organizations that have existed in Peru since ancient times; they have individual and collective rights

(1) Traducción: Nico Suárez Guerrero. Quechua, variante Cusco Collao

(2) Abogado por la Universidad Nacional San Antonio Abad del Cusco, Doctor en Derecho por la Universidad Andina del Cusco, Docente de la Escuela Profesional de Derecho de la UNSAAC y la UAC. Ericson.delgado@unsaac.edu.pe

(3) Estudiante de pregrado de Derecho. rubyzade@hotmail.com 
recognized both internationally and nationally. To protect these communities, the State has an obligation to create and manage a registry, which is the responsibility of the National Superintendency of Public Registries, in order to legally recognize, protect and develop their rights. However, there are certain aspects not covered in the legal framework; as well as bad practices in the Peruvian registry system. These violate the peasant communities' communal rights, among others, those related to linguistic rights, which clash with other international instruments recognized by the State, causing a lack of protection by the State as well as the need to implement adequate public policy.

Key words: Linguistic rights, peasant communities, registry system.

Pisi killqa: Chakra runakunaqa, hatun qutu kawsay runakuna kanku kay Peru suyupi, ñawpa llaqtakunamantapacha. Kanmi sapakamapa hayñin, tukuykunapa hayñin kay Peru suyupi, hinallataq hawa suyupi, amachakunankupaq. Suyu kamachiq, Superintendencia Nacional de los Registros Públicos institusionpaq'a sapakamanchistan qhawawanachis, chaymi rawuynin kay institusionpaq'a, hinatallataq hayñinchista hatunyachinanpaq, ichaq'a manan Iliw hayñinchistachu suyu kamachiqkunaqa amachawanchis, p'akisqan chakra runakunapa hayñinkuna, chaynatallataq simikunapa hayñinkunata, Peru suyupa kamachiykunaqa manan kuskachu hawasuyupa kamachiykunawan, chaymi chakra runakunaqa mana allin amachasqa kanku, chaymi Peru Suyupi mana allin hayñikuna kanchu, chaypaqmi mast'arinan allin políticas publicas nisqata. 


\section{Introducción}

El presente artículo pretende analizar los conflictos socio jurídicos que se presentan en el sistema registral peruano, como parte de la administración pública, ocasionados por la no observancia de los derechos lingüísticos de las comunidades campesinas andinas, prescritas en la Ley $\mathrm{N}^{\circ} 29735$, que regula el uso, preservación, desarrollo, recuperación y difusión de las lenguas originarias del Perú; la cual establece el derecho de toda persona a usar su lengua originaria en los ámbitos público y privado, a ser atendida en su lengua materna, en los organismos o instancias estatales, a gozar y disponer de los medios de traducción directa o inversa que garanticen el ejercicio de sus derechos en todo ámbito (Ministerio de Cultura, 2016).

Asimismo, busca desarrollar y describir el marco normativo nacional e internacional, y las obligaciones y funciones que el Estado tiene para promover el respeto a la lengua originaria; buscando mejorar las condiciones en las que las Comunidades Campesinas y Nativas, en su propio idioma, accedan a un servicio de publicidad registral efectivo y de calidad.

Empezamos describiendo que las Comunidades Campesinas son organizaciones sociales, tradicionales y de interés público; que cuentan con existencia legal, personería jurídica, cuya regulación normativa y jurídica se encuentra dentro de la Constitución Política del Perú (1993); Ley General de las Comunidades Campesinas, Ley $N^{\circ}$ 24656; Ley de Comunidades Nativas, Ley $\mathrm{N}^{\circ}$ 22175.

Cabe mencionar que una Comunidad Campesina o Nativa, para su existencia como sujeto de derecho, debe formalizar su existencia mediante el acto legal administrativo de la inscripción registral y de ello desprende su reconocimiento oficial. Si bien la mayoría de estas se encuentran registradas por el Estado, sin embargo, se evidencian tres problemas como: casos en las que algunos sujetos de derechos de ambos tipos (Comunidad Campesina o Nativa) aún no han sido inscritas como tales; que tienen dificultades para su correcta inscripción, o; estando inscritas, requieren actualizar, modificar, cancelar o inscribir nuevos actos jurídicos relativos a su personería jurídica o al derecho de propiedad que tienen.

El problema se acentúa cuando ambos sujetos de derecho se encuentran alejadas o completamente al margen de la acción del Estado, por ello, no logran iniciar y, mucho menos, concluir el procedimiento registral para inscribir los diferentes actos materia de inscripción, sean éstos constitutivos (obligatorios) o meramente declarativos, tanto en el registro de personas jurídicas como en el registro de predios.

Una de las fuentes más determinantes de esta problemática socio jurídica se debe al conjunto de la deficiente prestación de servicio de publicidad registral que brinda la Superintendencia Nacional de los Registros Públicos (SUNARP), la 
vulneración a los derechos lingüísticos, y la inobservancia del idioma nativo ya sea de una Comunidad Campesina o Nativa, por la administración pública. Se debe sumar, también, los obstáculos impuestos por el Sistema Registral Peruano para legalizar tanto su personería jurídica, como la inscripción de sus propiedades territoriales en el registro correspondiente.

Por otro lado, en la práctica se aprecia que gran parte de los procedimientos registrales iniciados por estos entes de imputación de derechos y deberes, no logran una calificación positiva de inmediato en el registro correspondiente; vale decir, los títulos son observados y/o tachados por adolecer de defectos, tanto de forma, como de fondo. Cabe mencionar que estos problemas podrían ser previstos, antes de su presentación e inicio administrativo, si se utilizaría un adecuado canal de comunicación, respetando los derechos lingüísticos de las Comunidades Campesinas y nativas. Cabe incidir que, el servicio de publicidad registral brindado por la SUNARP no es acorde con la realidad lingüística e idiosincrática de estos sujetos de derecho, ya que solo se realiza en el idioma castellano, impidiendo una real y efectiva comunicación entre esta entidad administrativa y los usuarios de las Comunales Campesinas o nativas.

Debe considerarse que el empleo de la lengua originaria de los pueblos autóctonos o nativos, posibilita un servicio idóneo y efectivo, ergo, afianza y fortalece la inclusión social y la seguridad jurídica, razón de ser de la SUNARP.

Algunos fundamentos constitucionales del presente trabajo vienen a ser el reconocimiento de algunas premisas materiales, sociales y jurídicas: el Estado peruano es un país pluricultural y multilingüe con una población que supera los 4 millones de hablantes de alguna lengua originaria; las lenguas originarias constituyen la expresión más rica de nuestra diversidad y manifestación cultural; el reconocimiento de esta premisa social se encuentra en la Constitución Política del Perú (1993), tipificado en el artículo 2, incisos 2 y 19.

Tal como lo expone Vásquez Medina (2015), estas premisas develan con absoluta claridad que el uso de las lenguas originarias por personas o ciudadanos integrantes de estas organizaciones jurídicas es un derecho fundamental que recién se viene desarrollando normativamente; he ahí que este reconocimiento recién se está plasmando en políticas, instrumentos y prácticas concretas promovidas desde el mismo Estado.

En una reciente tesis (Castillo Gamarra, 2017) se alcanzan algunas definiciones acerca de nuestro tema. En esta coherencia, este autor cita a Soriano Diaz (2017) cuando define que el derecho al uso de la propia lengua es:

"Aquel derecho que tienen todas las personas a expresarse y comunicarse en su misma lengua. Que se concreta con una serie de 
derechos lingüísticos. Los derechos lingüísticos son las manifestaciones o vías de derecho de este genérico a la lengua propia ante los poderes públicos, el derecho a recibir enseñanza en la lengua propia y el derecho a ser informado en la lengua propia de los medios de comunicación social (...) Los derechos lingüísticos podrán ser considerados como derechos humanos, con facilidad, puesto que derivan del progresivo enriquecimiento de los derechos de la primera generación o derechos de libertad, pero tendrán dificultad en ser catalogados como derechos fundamentales, propiamente dichos en nuestro ordenamiento jurídico, a los que pudiese aplicar la protección especial indicada por el constituyente en cuanto contenido esencial, las garantías procesales, la reserva legal, la reforma constitucional, etc." (p. 59)

De igual manera (Castillo Gamarra, 2017), refiere:

"Sobre el tema Félix Julca Guerrero sostiene que la posesión de un idioma propio es un derecho y parte vital de la identidad étnica de todo un pueblo; el lenguaje es una creación social que expresa y sistematiza experiencias colectivas milenarias; con todos sus contenidos y matices, de ahí que la defensa de los derechos lingüísticos y culturales se haya constituido una precaución en los últimos tiempos. En esa línea el Estado peruano promulga la ley 29735, mediante el cual dota a los pueblos indígenas de un instrumento legal que regula el uso, preservación, desarrollo, recuperación, fomento y difusión de las lenguas originarias en el Perú, que se traza como objetivo el de precisar el alcance de los derechos y garantías individuales y colectivas en materia lingüística, conforme lo ampara la Constitución Política del Perú en su articulo 48; ya que todas las lenguas originarias son la expresión de una identidad colectiva y de una manera distinta de concebir y de describir la realidad; por tanto gozan de las condiciones necesarias para su mantenimiento y desarrollo en todas las funciones. En nuestro país el derecho de los pueblos indígenas al uso de su lengua original: es reciente, por lo que la discusión en torno a la naturaleza jurídica del derecho a la lengua y si esta puede ser considerado como un derecho fundamental; si se tiene en cuenta nuestra gran diversidad lingüística, reflejados en los más de 47 lenguas que conocemos (...)" (p.61).

Respecto de nuestra carta Constitucional (1993), debemos manifestar que el uso del idioma originario está reconocido en el artículo 2, numeral 2 y 19, que prescribe, respectivamente:

"Toda persona tiene derecho: ... 2. A la igualdad ante la ley. Nadie debe ser discriminado por motivo de origen, raza, sexo, idioma, religión, opinión, condición económica o de cualquiera otra índole... 19. A su 
identidad étnica y cultural. El Estado reconoce y protege la pluralidad étnica y cultural de la Nación" (Constitución Política del Perú, 1993).

Esta premisa constitucional significa que el Estado peruano debe velar por la igualdad ante la ley sin importar el idioma y debe respetar las costumbres, valores, tradiciones que forman parte de la idiosincrasia de las Comunidades Campesinas y Nativas u otros grupos de personas; consecuentemente, según el marco constitucional es factible exigir el uso del idioma materno u originario en las entidades públicas.

Para la protección de las lenguas originarias el Estado ha emitido la Ley 29735, publicada el 05/07/11, "Ley que regula el uso, preservación, desarrollo, recuperación, fomento y difusión de las lenguas originarias del Perú", cuyo objetivo, según su propio artículo $1^{\circ}$ es el de precisar el alcance de los derechos y garantías individuales y colectivas que, en materia lingüística, se establecen en el artículo 48 de la Constitución Política del Perú (1993); precisando además que, todas las lenguas originarias son la expresión de una identidad colectiva y una manera distinta de concebir y de describir la realidad, por tanto gozan de las condiciones necesarias para su mantenimiento y desarrollo en todas las funciones.

Desde su aprobación se han venido generando acciones desde Educación y Cultura para implementar esta importante ley que marca un hito en la política lingüística nacional. (Vásquez Medina, 2015)

Como se indica, el Estado ha venido desarrollando acciones para la implementación de la referida ley enfocándose en el sector Educación y Cultura, tal es el caso de la Resolución Ministerial Nº75-2015/MC que aprueba la Directiva sobre el "Procedimiento para el uso y fomento de las lenguas indígenas u originarias en la prestación de servicios al público en el Sector Cultura"; sin embargo, sería altamente recomendable que el Estado dicte medidas similares para los otros sectores de mayor afluencia e interrelación con las Comunidades Campesinas y Nativas, como es el caso de los registros públicos.

El Ministerio de Cultura cuenta con una Dirección de Lenguas Indígenas encargada de promover e implementar acciones para el desarrollo y uso de las lenguas indígenas y originarias de los pueblos indígenas del país, fomentando su aprendizaje.

En el documento titulado "La implementación de derechos lingüísticos para la mejora de los servicios públicos y la recuperación y fortalecimiento de lenguas indígenas" (Vásquez Medina, 2015) se hace un recuento de las principales acciones impulsadas por algunas instituciones públicas con la asistencia técnica de la Dirección de Lenguas Indígenas, entre ellas el Poder Judicial, el Registro Nacional de Identificación 
y Estado Civil, el Jurado Nacional de Elecciones, el Ministerio de Desarrollo e Inclusión Social, Ministerio de Salud y Ministerio de Educación, destacando las acciones a cargo del Poder Judicial implementadas por la Oficina Nacional de Justicia de Paz y Justicia Indígena, como por ejemplo: la especialización de traductores e intérpretes para una justicia intercultural, la creación del registro de peritos en lenguas indígenas, traducciones, capacitación a jueces de paz, la suscripción de un convenio marco y específico para impulsar lenguas en diversos protocolos.

\section{Comunidades Campesinas y Nativas}

Según la Ley 24656, Ley General de Comunidades Campesinas, las Comunidades Campesinas son "(...) organizaciones comunales de interés público con existencia legal y personalidad jurídica, integradas por familias que habitan y controlan un territorio, ligadas generalmente por vínculos ancestrales, sociales, económicos y culturales, expresadas en la propiedad comunal de la tierra, el trabajo comunal, la ayuda mutua y el desarrollo de actividades agropecuarias y multisectoriales" (Congreso de la Republica del Peru, 1987). Agrega, además a esta concepción, que el ámbito geográfico único en nuestro territorio peruano, hace que estas comunidades se establezcan entre las vertientes de la gran cadena montañosa de los Andes, otorgándoles acceso a diferentes pisos altitudinales, manejo de recursos diversos y con ello diferentes formas de organización social y cultural, acrecentando así una cultura variada y diferentes formas de uso territorial.

Es necesario entender que el Perú es un país diverso, ya sea en torno a lo cultural o geográfico, y es de ahí que la tratativa comunal no es aplicable de la misma forma a las Comunidades Nativas. Para aclarar ese punto es necesario diferenciar a las Comunidades de la sierra y las Comunidades Nativas.

Ahora bien, cabe hacer la diferencia correspondiente entre una Comunidad Campesina y una Nativa, tales como que las primeras existen en la Costa y la Sierra del Perú, mientras las segundas se encuentran en la Selva. En la legislación especial, Ley 24656 de Comunidades Campesinas (1987) y Ley 22175 de Comunidades Nativas (1978), se pueden encontrar sustanciales diferencias entre ambas: 1.- Pueden establecerse Comunidades Campesinas en cualquier parte, es decir, en el campo, establecido por la Ley 24656. 2.- Las Comunidades Nativas tienen su origen en grupos tribales de Selva y Ceja de Selva, establecido por el Art. 8 Ley 22175, 3.- Las Comunidades Campesinas controlan y habitan determinado territorio, siendo comunidades establecidas en un determinado espacio, así lo establece el artículo 2 de la Ley 24656. 4.- Las Comunidades Nativas pueden tener, en alguno de los casos carácter sedentario, la superficie que actualmente ocupan para desarrollar sus actividades agropecuarias, de recolección, caza y pesca y cuando realicen migraciones estacionales, la totalidad de la superficie donde se establecen al efectuarlas, según lo dispuesto en el art. 10 del Decreto Ley 22175. 
No obstante, a la existencia de estas diferencias, sin embargo, también ambas instituciones jurídicas tienen una semejanza: que, sus territorios son objetos de expropiación, siempre que se acredite necesidad o utilidad pública.

Teniendo en cuenta lo referido, la forma de registro de ambos tipos de comunidades presentes en el Perú no puede ser similar. En el caso de las Comunidades Nativas, por ejemplo, la delimitación territorial es más difícil, pues al ser grupos sedentarios o de migraciones la delimitación de sus territorios es más complicada, muchas de estas comunidades no solo abarcan un mismo territorio, sino que lo comparten con otros grupos étnicos. Eso no implica que, en el caso de las Comunidades Campesinas asentadas en la costa y sierra, sea más fácil la delimitación, pues muchos de éstos terrenos comunales no tienen un espacio limítrofe definido; éstos límites, están determinados por elementos de la geografía o denominaciones toponímicas, lo cual hace que sucedan conflictos limítrofes entre comunidades que se agravan más cuando éstas limitan con otras regiones cercanas como el caso entre Cusco y Puno.

\section{Comunidades Campesinas en la legislación peruana}

Nuestro Código Civil, expresa, que: "Las comunidades campesinas y nativas son organizaciones tradicionales y estables de interés público, constituidas por personas naturales y cuyos fines se orientan al mejor aprovechamiento de su patrimonio, para beneficio general y equitativo de los comuneros, promoviendo su desarrollo integral" (Código Civil peruano, art. 134, 1984).

La Ley de Comunidades Campesinas tiene una definición que no dista mucho a la citada en el Código Civil, en ella se menciona que: Las Comunidades Campesinas son organizaciones de interés público, con existencia legal y personería jurídica, integrados por familias que habitan y controlan determinados territorios, ligadas por vínculos ancestrales, sociales, económicos y culturales, expresados en la propiedad comunal de la tierra, el trabajo comunal, la ayuda mutua, el gobierno democrático (Ley №24656, 1987).

Del artículo 134 del Código Civil podemos resaltar la expresión "las comunidades campesinas son organizaciones tradicionales", es decir, no elabora un concepto nuevo de Comunidades en nuestro país, sino reconoce que éstas ya tenían una forma organizativa anterior a la creación del mismo Estado. La ley general de comunidades campesinas, agrega además, que los miembros -las familias- de la comunidad están "ligadas por vínculos ancestrales, sociales, económicos y culturales, expresados en la propiedad comunal" lo cual evidentemente resalta que el Estado reconoce que una comunidad no sólo es una organización social, sino que conlleva dentro de sí un pasado histórico-cultural que debería ser respetado y si es posible normado debidamente para evitar conflictos entre el propio Estadoy las comunidades. 
Nuestra Carta Magna (1993) en su artículo 2 inciso 19 menciona que toda persona tiene derecho: "A su identidad étnica y cultural. El Estado reconoce y protege la pluralidad étnica y cultural de la Nación". En ese entender, las leyes reconocen que las personas peruanas, ya sea individual u organizada en comunidades, no son homogéneas, tiene una identidad étnica cultural y además diversa, por lo cual, no se pueden establecer, rígidamente procesos homogéneos para todos; pues si eso sucedería, sería un acto contra la ley misma. Los mecanismos pluriculturales que el Estado toma para poder empoderar a las poblaciones comunales y evitar sesgos legales son, uno de ellos, el establecimiento del llamado "derecho consuetudinario".

\section{Lenguas indígenas u originarias}

Se entiende por lengua, al conjunto sistematizado y estructurado de signos lingüísticos que emplea una colectividad humana para relacionarse e identificarse como parte de un grupo social y cultural. En ese entender Saussure define a la lengua como el "tesoro depositado por la práctica del habla en los sujetos que pertenecen a una misma comunidad, un sistema gramatical que existe virtualmente en cada cerebro o, más exactamente, en los derechos de un conjunto de individuos, pues la lengua no está completa en ninguno solo existe perfecta en la masa" (SAUSSURE, 1945).

Entonces, podemos decir que la lengua presenta una íntima relación con la identidad cultural y por ende con la cultura, al ser esta un medio de comunicación con todas las culturas, las mismas que están identificadas por una lengua, que posibilita la existencia y con ello la relación estrecha de un grupo concreto de habitantes.

Así pues "las lenguas expresan las visiones de la sociedad de que somos parte $y$, en ese sentido, forman parte también de las cosmovisiones de los pueblos originarios para dar sentido a la vida y al entorno holístico que los rodea" (D.S. N 005-2017-MC). Actualmente, Perú cuenta con una variada y abundante diversidad lingüística debido a las muchas comunidades andinas y nativas que la habitan, las cuales emplean su propio idioma, caracterizándolas de otro grupo étnico.

Se denominan lenguas indígenas u originarias a aquellas que tuvieron su origen en la época anterior a la conquista y que perduraron intactas a pesar del tiempo, de la imposición del idioma español y la discriminación; siendo trasmitidas de generación en generación aun cuando el idioma predominante es el castellano o español. Actualmente nuestro ordenamiento jurídico las protege y regula, encabezado por la Constitución Política del Perú (1993) y la Ley 297335, que regula el uso, preservación, desarrollo, recuperación, fomento y difusión de las lenguas originarias del Perú, garantiza el ejercicio de los derechos lingüísticos de manera individual y colectiva, así como el derecho de todas las personas a usar su lengua en todos los ámbitos (D.S. Nº05-2017-MC). 
De acuerdo a la base de datos de pueblos indígenas u originarios "en el Perú, hasta la fecha, se han identificado 48 lenguas indígenas u originarias (...). De las 48 lenguas, 4 se hablan en los Andes, siendo el quechua aquella que es hablada en casi todo el país, y 44 se hablan en la Amazonía" (Ministerio de Cultura, Perú, 2010).

\section{Marco normativo internacional de protección a las Comunidades Campesinas y a los derechos lingüísticos}

A nivel internacional, existen varios instrumentos jurídicos que reconocen los derechos de las Comunidades Campesinas y Nativas, que son fuente normativa vinculante para que los Estados parte desarrollen mecanismos políticos, jurídicos y administrativos para hacer posible la aplicación de la protección de los derechos mencionados.

Entre los cuales tenemos: la Declaración Universal de los Derechos Humanos, la Declaración de las Naciones Unidas sobre los Derechos de los Pueblos Indígenas (2007), en la cual se prescribe en el artículo 1: Los indígenas tienen derecho, como pueblos o como individuos, al disfrute pleno de todos los derechos humanos y las libertades fundamentales reconocidos en la Carta de las Naciones Unidas, la Declaración Universal de Derechos Humanos y las normas internacionales de derechos humanos. De ésta forma, y sin perífrasis, las Naciones Unidas establecen la protección de derechos de los pueblos indígenas que, en el caso peruano, se aplican a las Comunidades Campesinas y Nativas, las cuales como se referenció anteriormente, son reconocidas por el Estado mediante la Constitución Política y diversas leyes.

De la misma forma, en el artículo 4 de la referida Declaración se hace mención a la autodeterminación, empoderamiento y la libre determinación de sus propios acuerdos: "Los pueblos indígenas...tienen derecho a la autonomía o al autogobierno en las cuestiones relacionadas con sus asuntos internos y locales" (art.4). Para hacer efectivo lo citado, el artículo 8, el inciso 2 menciona a la letra: "Los Estados establecerán mecanismos eficaces para la prevención y el resarcimiento de: a) Todo acto que tenga por objeto o consecuencia privarlos de su integridad como pueblos distintos o de sus valores culturales o su identidad étnica; b) Todo acto que tenga por objeto o consecuencia desposeerlos de sus tierras, territorios o recursos". En ese entender, todos los Estados deben proteger y además entender los valores culturales que son parte de su identidad cultural, incluyendo las tierras que poseen pues éstas no se desvinculan del individuo, sino que forman parte de su identidad, tanto social, cultural y económica.

El derecho consuetudinario es reconocido de similar forma, pues proviene una larga transmisión oral. La declaración de las Naciones Unidas, nos dice: "Los pueblos indígenas tienen derecho a revitalizar, utilizar, fomentar y transmitir a las generaciones futuras sus historias, idiomas, tradiciones orales, filosofías...y a atribuir 
nombres a sus comunidades, lugares y personas, así como a mantenerlos" (art. 13, inc.1). De esta forma, los Estados, deben tomar en cuenta que la trasmisión de dichos valores y la denominación de sus territorios son esenciales para el desarrollo pleno de las Comunidades; y de acuerdo a ello, las leyes también deben configurar sus disposiciones tomando en cuenta los modos de vivir y conservación de sus espacios geográficos, éstos son transcritos en acción mediante el derecho consuetudinario.

Otro documento internacional que protege los derechos de las Comunidades, es el Convenio N ${ }^{\circ} 169$ de la OIT sobre Pueblos Indígenas y Tribales (1989) el cual, si bien es cierto, no hace referencia expresa a las Comunidades Campesinas; hace una interesante mención de los pueblos distintos a la oficialidad nacional; es así que menciona:

El presente Convenio se aplica: a) a los pueblos tribales en países independientes, cuyas condiciones sociales, culturales y económicas les distingan de otros sectores de la colectividad nacional, y que estén regidos por sus propias costumbres o tradiciones o por una legislación especial; b) a los pueblos en países independientes, considerados indígenas por el hecho de descender de poblaciones que habitaban en el país o en una región geográfica en la época de la conquista o la colonización o del establecimiento de las actuales fronteras estatales y que, cualquiera que sea su situación jurídica." (art.1, inc.1)

En el caso del Perú, ambas nociones se aplican, pues las Comunidades Campesinas son organizaciones independientes y que evidentemente se distinguen de otros sectores sociales, y además su existencia precede a la conquista española, conservan sus instituciones sociales económicas y políticas por "derecho consuetudinario". Para reforzar el reconocimiento de las Comunidades frente al Estado, en el convenio citado hace mención que "La conciencia de su identidad indígena o tribal deberá considerarse un criterio fundamental para determinar los grupos a los que se aplican las disposiciones del presente Convenio" (art.1 inc2). De esta forma, y en sentido estricto, se impone a los estados que el reconocimiento de una Comunidad, no puede limitarse a un proceso solo nominativo legal; sino que un aspecto fundamental es que ellos se reconozcan como pueblo, con sus propias costumbres y tradiciones, que no sólo deben ser reconocidas y protegidas; sino respetadas y aceptadas para su legalidad.

Para hacer efectiva esa mención, también indica: "Los gobiernos deberán asumir la responsabilidad de desarrollar, con la participación de los pueblos interesados, una acción coordinada y sistemática con miras a proteger los derechos de esos pueblos y a garantizar el respeto de su integridad." (art.2, inc1) Y agregamos además: "Deberán adoptarse las medidas especiales que se precisen para salvaguardar las personas, las 
instituciones (...) las culturas y el medio ambiente de los pueblos interesados." (art. 4, inc1). Con estas referencias claras, los Estados no pueden poner trabas legales o administrativas para proteger a las Comunidades; además deben informarles de forma correcta y oportuna de sus derechos y cómo hacerlos respetar.

Si bien es cierto, parte importante del reconocimiento de las Comunidades tiene que ver con el reconocimiento de sus derechos y cultura, ésta se extiende al respeto de los derechos lingüísticos, obligando a los estados a implantar mecanismos de tipo administrativo para un adecuado respeto y protección a la lengua originaria:

A continuación, haremos mención a las normas supranacionales y transcripción de los principales artículos que regulan y protegen los derechos lingüísticos:

\section{a. Declaración Universal de Derechos Humanos}

"Artículo 2.- Toda persona tiene todos los derechos y libertades proclamados en esta Declaración, sin distinción alguna de raza, color, sexo, idioma, religión, opinión política o de cualquier otra índole, origen nacional o social, posición económica, nacimiento o cualquier otra condición. Además, no se hará distinción alguna fundada en la condición política, jurídica o internacional del país o territorio de cuya jurisdicción dependa una persona, tanto si se trata de un país independiente, como de un territorio bajo administración fiduciaria, no autónomo o sometido a cualquier otra limitación de soberanía". (Declaración Universal de Derechos Humanos, 1948).

Marco normativo internacional adoptada y proclamada por la Asamblea General de las Naciones Unidas en la resolución 217 A III, del 10 de diciembre de 1948; donde se establece tres situaciones jurídicas: 1.- Que, toda persona tiene derecho a la vida, la libertad, la propiedad, la integridad persona, etc. 2.- Que, toda persona es sujeto de derechos establecidos en la Declaración, independientemente a su raza, color, sexo, idioma, religión, opinión política, origen nacional o social, posición económica, etc. 3.- Que, está proscrito cualquier distinción fundada en condición política, jurídica, o internacional del país o territorio de donde procesa un ser humano, ya sea que se trate de un país independiente o dependiente.

\section{b. Pacto Internacional de Derechos Civiles y Políticos}

"Artículo 26.- Todas las personas son iguales ante la ley y tienen derecho sin discriminación a igual protección de la ley. A este respecto, la ley prohibirá toda discriminación y garantizará a todas las personas protección igual y efectiva contra cualquier discriminación por motivos de raza, color, sexo, idioma, religión, opiniones políticas o de cualquier 
índole, origen nacional o social, posición económica, nacimiento o cualquier otra condición social" (Pacto Internacional de Derechos Civiles y Políticos, 1976).

En este marco normativo internacional, adoptado por la Asamblea General de las Naciones Unidas del 16 de diciembre de 19766, donde se establece, en su artículo 26 los siguientes principios: 1.- Que, todas las personas son iguales ante le ley y tienen el mismo derecho, sin distinción ni discriminación, a igual protección ante la ley; 2.- Que, la ley prohíbe cualquier forma de discriminación y garantiza a todas las personas protección igual y efectiva contra una discriminación por motivos de raza, religión, color, sexo, idioma, origen nacional o social o posición económica.

En general, también, en este marco normativo se garantiza el derecho humano de igualdad ante la ley, ergo, también las personas integrantes de comunidades campesinas y nativas tienen el mismo derecho que un ciudadano común y corriente.

c. Pacto Internacional de Derechos económicos, sociales y culturales "Artículo 2.- (...) 2. Los Estados Partes en el presente Pacto se comprometen a garantizar el ejercicio de los derechos que en él se enuncian, sin discriminación alguna por motivos de raza, color, sexo, idioma, religión, opinión política o de otra índole, origen nacional o social, posición económica, nacimiento o cualquier otra condición social". (Pacto Internaional de Derechos Socilaes, Económicos y Culturales, 1976).

En este marco normativo internacional, se establece en el artículo 2 que: los estados partes de dicho Pacto se comprometen a garantizar el ejercicio pleno y efectivo de todos los derechos que en él se encuentran, tales como el derecho a la igualdad, el derecho a la propiedad privada, el derecho a la vida, el derecho a la libertad, el derecho al debido proceso, etc.; asimismo, se establece que para el ejercicio de dichos derechos no existe ninguna distinción o discriminación por motivos de raza, sexo, idioma, religión u opinión política.

\section{d. Convenio 169 de la OIT}

"Artículo 28.- (...) 1. Siempre que sea viable, deberá enseñarse a los niños de los pueblos interesados a leer y a escribir en su propia lengua indígena o en la lengua que más comúnmente se hable en el grupo a que pertenezcan. Cuando ello no sea viable, las autoridades competentes deberán celebrar consultas con esos pueblos con miras a la adopción de medidas que permitan alcanzar este objetivo. 2 . Deberán tomarse medidas adecuadas para asegurar que esos pueblos tengan la oportunidad de llegar a dominar la lengua nacional o una 
de las lenguas oficiales del país. 3. Deberán adoptarse disposiciones para preservar las lenguas indígenas de los pueblos interesados y promover el desarrollo y la práctica de las mismas". (Convenio N ${ }^{\circ} 169$ de la Organización Internacional del Trabajo, 2009).

Principio desarrollado por la OIT, donde se establece que cada país tiene la obligación de enseñar a los niños de los pueblos interesados a leer y a escribir en su propia lengua indígena o en la lengua que más frecuentemente se habla en el grupo social o étnico al que pertenezcan. $\mathrm{Si}$ esta premisa no es viable, todas las autoridades competentes deberán celebrar consultas populares con esos pueblos con miras a la adopción de medidas que permitan alcanzar el objetivo señalado; es decir, la necesidad de educar a los niños en su idioma genuino.

La otra obligación que tiene el Estado es tomar medidas adecuadas para asegurar que estos pueblos tengan la oportunidad de llegar a dominar la lengua nacional o una de las lenguas oficiales del país. Por último, también se deberá adoptar disposiciones donde se establezcan políticas y mecanismos a fin de preservar las lenguas indígenas de los pueblos interesados y promover el desarrollo y la práctica de las mismas.

e. Declaración sobre los derechos de las personas pertenecientes a minorías nacionales o étnicas, religiosas y lingüísticas

"Artículo 1.- Los Estados protegerán la existencia y la identidad nacional o étnica, cultural, religiosa y lingüística de las minorías dentro de sus territorios respectivos y fomentarán las condiciones para la promoción de esa identidad. 2. Los Estados adoptarán medidas apropiadas, legislativas y de otro tipo, para lograr esos objetivos. artículo 2.- Las personas pertenecientes a minorías nacionales o étnicas, religiosas y lingüísticas (en lo sucesivo denominadas personas pertenecientes a minorías) tendrán derecho a disfrutar de su propia cultura, a profesar y practicar su propia religión, y a utilizar su propio idioma, en privado y en público, libremente y sin injerencia ni discriminación de ningún tipo. Las personas pertenecientes a minorías tendrán el derecho de participar efectivamente en la vida cultural, religiosa, social, económica y pública (...)" (Declaración sobre los derechos de las personas pertenecientes a minorías nacionales o étnicas, religiosas y lingüísticas, 1992).

En este marco normativo se prescribe: primero: que, los Estados salvaguardarán la identidad nacional, cultural, étnica, religiosa y lingüística de las minorías en el interior de sus territorios respectivos; así como fomentarán las condiciones para la promoción de esta identidad. Luego, en el artículo segundo se establece que: es obligación de los Estados de adoptar medidas legislativas, normativas, reglamentarias, para lograr esos objetivos. 
Tambien en el artículo segundo se prescribe que: las personas pertenecientes a minorías nacionales o étnicas, religiosas y lingüísticas, denominadas personas pertenecientes a minorías, tienen derecho de disfrutar su propia cultura, a pregonary practicar su propia religión, y ha utilizar su propio idioma, de forma libre y sin ninguna injerencia o discriminación de ningún tipo.

Asimismo, se precisa que, las personas pertenecientes a minorías tendrán el derecho a participar efectivamente en la vida cultural, religiosa, social, económica y publica.

\section{f. Convenio Europeo de Derechos Humanos}

"Artículo 14.- Prohibición de discriminación.- El goce de los derechos y libertades reconocidos en el presente Convenio ha de ser asegurado sin distinción alguna, especialmente por razones de sexo, raza, color, lengua, religión, opiniones políticas u otras, origen nacional o social, pertenencia a una minoría nacional, fortuna, nacimiento o cualquier otra situación" (Convención Europea de Derechos Humanos, 1948).

En este marco normativo se desarrolla algunos principios tales como: Que, esta terminantemente prohibido el trato discriminatorio por condición de sexo, raza, color, condición económica, religión y para nuestro caso, por condición de lengua.

Luego, se establece que los derechos y libertades reconocidos en este marco normativo se ejercen de forma efectiva y con igualdad ante la ley.

g. Protocolo $\mathrm{N}^{\circ} 12$ al Convenio para la Protección de los Derechos Humanos y de las Libertades Fundamentales

"Artículo 1.- Prohibición general de la discriminación. 1. El goce de los derechos reconocidos por la ley ha de ser asegurado sin discriminación alguna, especialmente por razones de sexo, raza, color, lengua, religión, opiniones políticas o de otro carácter, origen nacional o social, pertenencia a una minoría nacional, fortuna, nacimiento o cualquier otra situación. 2. Nadie podrá ser objeto de discriminación por parte de una autoridad pública, especialmente por los motivos mencionados en el párrafo 1 (Protocolo numero 12 al Convenio para la Protección de los Derechos Humanos y de las Libertades Fundamentales, 2008).

Marco normativo donde se reconoce que el goce de los derechos regulados por ley ha de ser asegurados sin discriminación de ningún tipo. Refiere también que la discriminación por razones de raza, sexo, color, religión, opinión política y de otro carácter. Luego, se establece que nadie podrá ser discriminado por la autoridad pública, por los motivos de raza, sexo, color, condición económica, lengua, etc.

h. Declaración Universal de Derechos Lingüísticos Unesco - Conferencia Mundial de Derechos Lingüísticos.

"TíTULO PRELIMINAR: Artículo 1. Esta Declaración entiende como 
comunidad lingüística toda sociedad humana que, asentada históricamente en un espacio territorial determinado, reconocido o no, se auto identifica como pueblo y ha desarrollado una lengua común como medio de comunicación natural y de cohesión cultural entre sus miembros. La denominación lengua propia de un territorio hace referencia al idioma de la comunidad históricamente establecida en este espacio. 2. Esta Declaración parte del principio que los derechos lingüísticos son a la vez individuales y colectivos, y adopta como referente de la plenitud de los derechos lingüísticos el caso de una comunidad lingüística histórica en su espacio territorial, entendido éste no solamente como área geográfica donde vive esta comunidad, sino también como un espacio social y funcional imprescindible para el pleno desarrollo de la lengua (...) (Declaración Universal de Derechos Linguisticos, 1996).

Mediante el presente documento normativo, la Conferencia Mundial de Derechos Lingüísticos de la UNESCO, define a la comunidad lingüística como: toda sociedad humana asentada históricamente en un espacio territorial determinado, reconocido o no, se auto identifica como pueblo y ha desarrollado una lengua común, como medio de comunicación natural. Por otro lado, también se hace una definición de que la lengua propia es el idioma de una comunidad históricamente asentada en un territorio o espacio geográfico.

La premisa que fundamente dicha norma internacional viene a ser que: Que, los derechos lingüísticos son a la vez individuales y colectivos, y adopta como referencia de la plenitud de los derechos lingüísticos el caso de una comunidad lingüística histórica en su espacio geográfico. Ahora bien, hay que entender que el territorio comunal no solo se define como un área área geográfica donde vive esta comunidad; sino también como un espacio social y funcional sine quanon para el efectivo desarrollo de la lengua.

i. Declaración Americana de los Derechos y Deberes del Hombre "Derechos de igualdad ante la ley. Artículo II. Todas las personas son iguales ante la Ley y tienen los derechos y deberes consagrados en esta declaración sin distinción de raza, sexo, idioma, credo ni otra alguna" (Declaración Americana de los Derechos y Deberes del Hombre, 1948). En este marco normativo también se precisa el principio fundamental del derecho a la igualdad; es decir, para la aplicación de la ley no serán determinantes las diferencias entre raza, sexo, idioma, credo, ni de ninguna otra índole.

j. Convención Americana sobre Derechos Humanos (Pacto de San José) "Artículo 24. Igualdad ante la ley. Todas las personas son iguales ante la ley. En consecuencia, tienen derecho, sin discriminación, a igual protección de la ley" (Convención Americana sobre derechos Humanos, 1978). 
El Pacto de San José, también precisa el derecho humano a la igualdad; es decir, la aplicación y el trato hacia un ser humano debe ser sin discriminación por razón de raza, sexo, condición económica, o idioma.

k. Carta Andina para la Promoción y Protección de los Derechos Humanos. "Discriminación e Intolerancia. Artículo 10.- Reafirman su decisión de combatir toda forma de racismo, discriminación, xenofobia y cualquier forma de intolerancia o de exclusión en contra de individuos o colectividades por razones de raza, color, sexo, edad, idioma, religión, opinión política, nacionalidad, orientación sexual, condición migratoria y por cualquier otra condición; $y$, deciden promover legislaciones nacionales que penalicen la discriminación racial. (Consejo Presidencial Andino, 2002). Por medio de este marco normativo se prohíbe todo tipo de racismo, discriminación, xenofobia y cualquier forma de intolerancia o de exclusión en contra de individuos o grupos humanos por razones de raza, color, sexo, edad, y lo más importante por razones de idioma.

Asimismo, en este marco normativo se establecen obligaciones a los estados de implementar un proceso político, cultural, educativo y legislativo para eliminar y sancionar la discriminación por razón de sexo, idioma, condición migratoria, orientación sexual, nacionalidad, opinión política, etc.

\section{Marco legal nacional sobre los derechos lingüísticos}

\section{a. Constitución Política del Perú de 1993}

"Artículo 2. Toda persona tiene derecho: (...) 2. A la igualdad ante la ley. Nadie debe ser discriminado por motivo de origen, raza, sexo, idioma, religión, opinión, condición económica o de cualquiera otra índole. (...) 19. A su identidad étnica y cultural. El Estado reconoce y protege la pluralidad étnica y cultural de la Nación. Todo peruano tiene derecho a usar su propio idioma ante cualquier autoridad mediante un intérprete. Los extranjeros tienen este mismo derecho cuando son citados por cualquier autoridad. (...) Artículo $48^{\circ}$.- Son idiomas oficiales el castellano $y$, en las zonas donde predominen, también lo son el quechua, el aimara y las demás lenguas aborígenes, según la ley" (Constitución Política del Perú, 1993).

Dentro del marco legal nacional tenemos la Constitución Política del Perú, Art. 2, numerales 2 y 19, señala: los derechos a la igualdad y a la identidad étnica y cultural, respectivamente. En el numeral 2 del artículo segundo, prescribe: todas las personas son sujetos de derecho, no importando para ello las diferencias en cuanto al sexo, color, raza, idioma, condición económica e identidad cultural 
b. Ley 29735. Ley que regula el uso, preservación, desarrollo, recuperación, fomento y difusión de las lenguas originarias del Perú "CAPÍTULO I.- Artículo 1. Objeto de la Ley: 1. La presente Ley tiene el objeto de precisar el alcance de los derechos y garantías individuales y colectivas que, en materia lingüística, se establecen en el artículo 48 de la Constitución Política del Perú (1993).1.1.Todas las lenguas originarias son la expresión de una identidad colectiva y de una manera distinta de concebir y de describir la realidad, por tanto, gozan de las condiciones necesarias para su mantenimiento y desarrollo en todas las funciones. Artículo 2. Declaración de interés nacional.- Declárase de interés nacional el uso, preservación, desarrollo, recuperación, fomento y difusión de las lenguas originarias del país. Artículo 3. Definición de lenguas originarias.- Para los efectos de la aplicación de la presente Ley, se entiende por lenguas originarias del Perú a todas aquellas que son anteriores a la difusión del idioma español y que se preservan y emplean en el ámbito del territorio nacional. artículo 4. Derechos de la persona.- 4.1 Son derechos de toda persona: a) Ejercer sus derechos lingüísticos de manera individual y colectiva b) Ser reconocida como miembro de una comunidad lingüística. c) Usar su lengua originaria en los ámbitos público y privado. d) Relacionarse y asociarse con otros miembros de la comunidad lingüística de origen. e) Mantener y desarrollar la propia cultura.f) Ser atendida en su lengua materna en los organismos o instancias estatales. g) Gozar y disponer de los medios de traducción directa o inversa que garanticen el ejercicio de sus derechos en todo ámbito. h) Recibir educación en su lengua materna y en su propia cultura bajo un enfoque de interculturalidad. i) Aprender el castellano como lengua de uso común en el territorio peruano. 4.2 La titularidad individual de estos derechos no impide el ejercicio colectivo de los mismos. De igual modo, el ejercicio de estos derechos no está supeditado a la aprobación del Mapa Etnolingüístico del Perú o el establecimiento del Registro Nacional de Lenguas Originarias, a que se refieren los artículos 5 y 8.

CAPÍTULO III.- Idiomas oficiales: artículo 9. Idiomas oficiales.- Son idiomas oficiales, además del castellano, las lenguas originarias en los distritos, provincias o regiones en donde predominen, conforme a lo consignado en el Registro Nacional de Lenguas Originarias. artículo 10. Carácter oficial. El que una lengua originaria sea oficial, en un distrito, provincia o región, significa que la administración estatal la hace suya y la implementa progresivamente en todas sus esferas de actuación pública, dándole el mismo valor jurídico y las mismas prerrogativas que al castellano. Los documentos oficiales que emite constan tanto en castellano como en la lengua originaria oficial, cuando esta tiene 
reglas de escritura, teniendo ambos el mismo valor legal y pudiendo ser oponibles en cualquier instancia administrativa de la zona de predominio. (...) Artículo 15. Uso oficial. 15.1 El Estado promueve el estudio de las lenguas originarias del Perú, procurando reforzar su uso en el ámbito público. 15.2 Las entidades públicas y privadas que prestan servicios públicos implementan, de modo planificado y progresivo, políticas y programas de capacitación o contratación para que en las zonas del país donde una lengua originaria sea predominante sus funcionarios y servidores públicos, así como los integrantes de las Fuerzas Armadas y Policía Nacional del Perú se puedan comunicar con suficiencia en esa lengua. 15.3 Las entidades públicas implementan progresivamente la publicación, en sus respectivas páginas web o portales, de las normas legales de su ámbito que incidan directamente en el quehacer de los integrantes de los pueblos originarios, en forma escrita y oral, en sus lenguas originarias; asimismo, difunden las normas que afectan derechos o establecen beneficios a favor de las comunidades, a través de los mecanismos orales o escritos, que resulten idóneos, según cada caso concreto. (...) Artículo 17. Medidas contra la discriminación.- El Estado implementa medidas efectivas que impidan la discriminación de las personas por el uso de las lenguas originarias" (Ley N 29735,2011$)$.

La Ley $\mathrm{N}^{\circ} 29735$ intenta regular el uso, preservación, desarrollo, recuperación fomento y difusión de las lenguas originarias del Perú. Esta propuesta reconoce al Perú como un país con una diversidad de lenguas; sin embargo, a pesar de este avance legislativo, el problema radica en que el Estado no tiene una estrategia de aplicación.

En efecto, hay un plazo para que la aplicación de la mencionada ley sea de forma progresiva, en torno a 40 o 60 lenguas que existirían en el país, es un intento de unificarlos, sin embargo, se prevé que habrá dificultades para formalizarlas.

Con esta ley, se exige que cada entidad administrativa y cada órgano tengan un traductor respectivo.

A este problema se suma que la mayoría de lenguas nativas están castellanizadas, la falta de presupuesto, la burocracia en el sistema administrativo, la falta de profesores que enseñen estas lenguas, etc. Volviendo al tema de la aplicación de la ley analizada, el primer paso para su aplicación será la contratación de maestros bilingües que trabajaran en los lugares más inhóspitos del Perú. También a esta problemática se suma la falta de infraestructura, el diseño de cursos de lingüística originaria de los pueblos campesinos y nativos.

También en esta función de aplicación, se deben inmiscuir los gobiernos 
subnacionales, quienes deberán diseñar una política tendente a identificar, y cuantificar el número de lenguas o idiomas existentes en sus respectivas jurisdicciones.

Cabe mencionar que la referida ley deroga el Decreto Ley $N^{\circ} 21156$, Ley que reconoce el quechua como lengua oficial de la República y la Ley $^{\circ} 28106$, Ley de Reconocimiento, preservación, fomento y difusión de las lenguas aborígenes.

Por otro lado, se reconoce que hoy son idiomas oficiales, además del castellano, las lenguas originarias en los Distritos, Provincias o Regiones en donde predominen, conforme a lo consignado en el Registro Nacional de Lenguas Originarias.

Por último, el poder ejecutivo tiene 60 días calendario para aprobar las normas reglamentarias para su aplicación.

\section{El Sistema Registral y las Comunidades Campesinas}

Para que una Comunidad sea reconocida, y con ello goce de todos los derechos reconocidos, sobre todo por el Estado, ésta debe ser registrada debidamente. Así lo establece, el Código Civil al normar a las Comunidades Campesinas y sus territorios: "Para la existencia legal de las comunidades se requiere, además de la inscripción en el registro respectivo, su reconocimiento oficial" (art. 135). Además en la parte final del artículo 136, se establece que: "Se presume que son propiedad comunal las tierras poseídas de acuerdo al reconocimiento e inscripción de la comunidad" (art.136)

Los procedimientos y demás documentos para registrar a las Comunidades pueden encontrarse en el Reglamento de la Ley General de Comunidades Campesinas (D.S No 008-91-TR, 1991) la cual, menciona: "será inscrita por resolución administrativa del órgano competente en asuntos de Comunidades del Gobierno Regional correspondiente, inscribirá en el Libro de Comunidades Campesinas y Nativas del Registro de Personas Jurídicas de la Oficina Registral" (art.2). El registro es de competencia del Gobierno Regional, y las acciones primeras para la inscripción están así referidos: "Para la inscripción de la Comunidad se requiere: a. Constituir un grupo de familias; $b$. Tener la aprobación de por lo menos los dos tercios de los integrantes de la Asamblea General; y c. Encontrarse en posesión de su territorio" (art.3)

Los documentos esenciales para dicha inscripción se indican en el citado reglamento de esta forma:

El Presidente de la Directiva Comunal, presentará solicitud, al órgano competente en asuntos de Comunidades del Gobierno Regional, acompañando los siguientes documentos: a. Copias legalizadas, por Notario o Juez de Paz de la localidad, de las siguientes actas de 
Asamblea General donde: - Se acuerda solicitar su inscripción como Comunidad Campesina, precisando el nombre; - Se aprueba el Estatuto de la Comunidad; $y$ - Se elige a la Directiva Comunal. b. Censo de población y otros datos según formularios proporcionados por el INDEC; y c. Croquis del territorio comunal con indicación de linderos y colindantes" (art.4)

Una vez presentado lo anterior es competencia del Gobierno Regional emitir una constancia, referida así en el Reglamento de Comunidades mencionado: "La obtención de una constancia que acredite la posesión del territorio comunal, otorgado por el órgano competente en materia de propiedad y tenencia de tierras rústicas del Gobierno Regional" (art.5, lit.b) y ello debe ser constatado ocularmente por la autoridad competente como consta en el mismo artículo: "Una inspección ocular para la verificación de los datos proporcionados por la Comunidad Campesina, evacuando el respectivo informe, con opinión sobre la procedencia o improcedencia de la inscripción de la Comunidad. (art.5, lit.c). En esta última parte, la noción del reconocimiento de los linderos, por parte de la comunidad, será esencial.

Una vez agotado el trámite ante el órgano competente en asuntos de comunidades del Gobierno Regional, se debe iniciar otro procedimiento administrativo en la Superintendencia Nacional de los Registros Públicos, solicitando la inscripción de la Comunidad en el Libro de Comunidades Campesinas y Nativas del Registro de Personas Jurídicas, en el marco de la Resolución del Superintendente Nacional de los Registros Públicos N 122-2013, la misma que aprueba la Directiva № 005-2013-SUNARP/SN "Directiva que regula la inscripción de los actos y derechos de las comunidades nativas".

En el Art. 5.2 de la referida Directiva, se regulan los actos inscribibles en el Libro de Comunidades Nativas y Campesinas, de la forma siguiente:

"Las comunidades nativas podrán inscribir los siguientes actos:

a) Su reconocimiento, estatuto y sus modificaciones;

b) El nombramiento de los integrantes de su junta directiva, y de los demás representantes o apoderados, su aceptación, remoción, suspensión, renuncia, el otorgamiento de poderes, su modificación, revocación, sustitución, delegación y reasunción de estos;

c) Las resoluciones judiciales referidas a la validez de los acuerdos inscribibles de la Comunidad Nativa;

d) En general, los actos o contratos que modifiquen el contenido de los asientos registrales o cuyo registro prevean las disposiciones legales o reglamentarias" (Directiva Nº 005-2013-SUNARP/SN , 2013). 
Debemos indicar, que los referidos actos inscribibles, así como los requisitos para su inscripción, son básicamente los mismos para las personas jurídicas no societarias, propiamente para las asociaciones, lo que significa que el sistema registral peruano da igual o similar tratamiento a las Comunidades Campesinas y a las personas jurídicas no societarias.

Los territorios de las Comunidades, no son inscritos en el libro de Comunidades Campesinas y Nativas; estos deben ser inscritos en el registro de predios. La DIRECTIVA 10 -2013-5UNARP/SN, en su numeral 6 y el punto 6.1 establece que "las Comunidades Campesinas se inscriben en el Registro de Predios de las oficinas registrales. El Registrador requerirá informe técnico a las áreas de catastro de las oficinas registrales involucradas" (DIRECTIVA Nº 10 -2013-5UNARP/SN, 2013).

Para facilitar los trámites y documentos; la SUNARP editó, acertadamente, la Guía General para la Inscripción de Actos y Derechos de las Comunidades Campesinas. En ésta guía, está basada e incluye además en su parte final la DIRECTIVA N ${ }^{\circ} 10-2013-S U N A R P / S N$, establece claramente aquellos documentos sustanciales para la inscripción de las Comunidades como son: el original o copia certificada de la Resolución de reconocimiento expedida por la Dirección Regional de Agricultura y; constancia de inscripción en el registro administrativo conteniendo los datos de la inscripción, solo cuando la Resolución de reconocimiento no los indique (SUNARP, 2016, pág. 16).

Además de los documentos anteriormente mencionados; estos deben incluir una copia del acta donde se establezca mediante la reunión la inscripción de la Comunidad, el estatuto respectivo y un documento que acredite la participación del quorum respectivo para la inscripción de la Comunidad.

Los terrenos son inscritos en el registro de predios. Para ello, se deben presentar, específicamente:

Para territorios de Comunidades Campesinas: a) actas de Colindancia, b) Plano del conjunto de la comunidad campesina, y c) memoria descriptiva.

Para predios rurales afectados por la reforma agraria adjudicados a comunidades campesinas: a) Título de propiedad, b) Plano geodiferenciado de la Red Geodesia Nacional c) Memoria descriptiva firmada por el verificador del Registro de Predios, visado por la Dirección Regional de Agricultura.

Para predios adquiridos por la Comunidad Campesina en el marco del derecho civil. a) Instrumentos públicos por un periodo ininterrumpido de cinco años, o títulos supletorios. b) plano y c) memoria descriptiva. 
Se establecen además requisitos adicionales: Para predios rurales ubicados en zonas catastradas a) Certificado de información catastral. Para predios rurales en zonas no Catastradas: a) Certificado negativo de catastro emitido por la autoridad competente. b) Plano perimétrico del predio. c) Memoria descriptiva (SUNARP, 2016, pág. 33).

También, un documento importante es el documento de Catastro, el cual es un Registro, catálogo o inventario del territorio, en el que se identifican a los predios mediante su descripción gráfica en planos. Gracias a ello se puede identificar a) Si el territorio de la Comunidad Campesina se encuentra inmatriculado en todo o en parte. b) Si existe superposición total o parcial del terreno que ocupa el territorio donde la Comunidad Campesina se encuentra. Si hay superposición el informe debe indicar la ubicación, superficie y perímetro. c) En caso que se señale que existe imposibilidad de determinar si el territorio de la Comunidad Campesina se encuentra inscrito, esta circunstancia no impedirá la inmatriculación solicitada (SUNARP, 2016, pág. 34).

Es cierto que, las exigencias para lograr las inscripciones relativas a las Comunidades Campesinas, tanto en el registro de personas jurídicas como en el de predios, son muy rigurosas y poco flexibles, prueba de ello son las múltiples observaciones y denegatorias a los títulos presentados por las Comunidades, ocasionando sobrecarga de expedientes en trámite y malestar en los usuarios; situación que se podría solucionar con una buena comunicación e información, y por qué no, en el idioma original de los comuneros, para ello la SUNARP debería implementar diversos mecanismos que procuren el uso del idioma propio de las Comunidades, brindando una buena orientación y/o información a través de un profesional con dominio en la lengua originaria requerida, o si ello no fuese posible, a través de un intermediario o interprete.

En el sitio web de la SUNARP, se aprecia que se vienen ejecutando varios programas de inclusión registral como es SUNARP te escucha, SUNARP en tu pueblo, brigada registral, entre otros; pero estas se realizan en idioma castellano y no se evidencia el uso de idiomas originarios para brindar orientación a las Comunidades Campesinas, hecho que debería ser potenciado para un conveniente respeto a los derechos lingüísticos de las Comunidades. Por lo que, urge la intervención del Ministerio de Cultura a través de la Dirección de Lenguas Indígenas, que trabaje de manera coordinada con la SUNARP para promover y difundir el uso de las lenguas originarias en los diferentes servicios que brinda la SUNARP, tal como lo ha venido realizando con otras instituciones públicas, como el Poder Judicial, el RENIEC, el JNE, etc. 


\section{Conclusiones}

A manera de conclusiones, nos permitimos realizar algunas sugerencias, para mejorar el servicio de brinda la administración pública, SUNARP, a las Comunidades Campesinas y Nativas, dentro del marco del respeto a los derechos lingüísticos:

- Los derechos lingüísticos se encuentran consagrados en varios dispositivos de carácter internacional; así como, lo reconoce nuestra legislación, por ello, el Estado debe fortalecer el respeto a las lenguas originarias, el quechua para el caso de la Región Cusco, promoviendo la recuperación, defensa y práctica, mediante la utilización en todos los ámbitos de la administración pública e incluso en las entidades privadas, que así lo requieran.

- Se debe mejorar los lazos inter instituciones, entre diferentes sectores del Estado, por ejemplo del Ministerio de Cultura a través de la Dirección de Lenguas Indígenas y la Superintendencia Nacional de Registros Públicos, celebrando convenios de cooperación, orientado a las Comunidades Campesinas y Nativas, en la condición de administrados o usuarios de ésta última entidad, para que puedan tener acceso a un servicio registral en su propia lengua y así propiciar el respeto a los derechos lingüísticos y fortalecer las políticas de inclusión que se vienen ejecutando.

- Resulta importante y necesaria la creación de mecanismos de intercomunicación especializada con la finalidad de brindar información y orientación a los administrados provenientes de las Comunidades Campesinas, con el apoyo de profesionales que hablen el idioma original, empleando intérpretes o traductores.

- Finalmente, los encargados de la calificación registral, deberían ser más flexibles y aplicar el criterio facilitador de las inscripciones, específicamente, cuando se trate de procedimientos iniciados por las Comunidades Campesinas.

\section{Referencias Bibliográficas y Legales}

CASTILLO GAMARRA, W. E. (2017). El derecho de los pueblos del Perú al uso de las lenguas originarias en el marco de la ley 29735. Ancash: (Tesis de pregrado) Universidad Nacional Santiago Antúnez de Mayolo. Perú. 
CONGRESO CONSTITUYENTE DEMOCRÁTICO. (29 de diciembre de 1993). Constitución Política del Perú . Lima, Perú.

CONGRESO DE LA REPÚBLICA DEL PERÚ. (13 de abril de 1987). Ley 24656. Ley General de Comunidades Campesinas. Lima, Lima, Lima.

CONSEJO PRESIDENCIAL ANDINO. (26 de julio de 2002). Carta Andina para la Promoción y Protección de los Derechos Humanos. Obtenido de http://www.sice.oas. org/labor/Carta\%20Andina.pdf

Convención Americana sobre derechos Humanos. (18 de julio de 1978). Pacto de San José . San José, Costa Rica.

Convención Europea de Derechos Humanos. (10 de diciembre de 1948). Asamblea General de las Naciones Unidas. Nueva York.

Convenio $\mathrm{N}^{\circ} 169$ de la Organización Internacional del Trabajo. (15 de septiembre de 2009). Conferencia Internacional del Trabajo. Ginebra.

D.S No 008-91-TR. (15 de Febrero de 1991). Aprueban Reglamento de la Ley General de Comunidades Campesinas. Lima, Perú.

D.S. Nº05-2017-MC. (s.f.). Decreto Supreo que aprueba la Política Nacional de Lenguas Originarias, Tradición Oral e Interculturalidad. Diario Oficial El Peruano. Lima, Perú.

Declaración Americana de los Derechos y Deberes del Hombre. (Mayo de 1948). IX Conferencia internacional americana. Bogota, Colombia.

Declaración sobre los derechos de las personas pertenecientes a minorías nacionales o étnicas, religiosas y lingüísticas. (18 de diciembre de 1992). Asamblea General en su Resolución 47/135. Nueva York.

Declaración Universal de Derechos Humanos. (10 de diciembre de 1948). Asamblea General de las Naciones Unidas. París, Francia.

Declaración Universal de Derechos Humanos. (10 de diciembre de 1948). Asamblea General de las Naciones Unidas. Resolución 217 A (III). París, Francia.

Declaración Universal de Derechos Linguisticos. (junio de 1996). Comité de Traducciones y Derechos Lingüísticos del PEN Club Internacional y el CIEMEN. Barcelona, España.

Directiva N005-2013-SUNARP/SN . (2013). “Directiva que regula la inscripción de los actos y derechos de las comunidades nativas".

DIRECTIVA N 10 -2013-5UNARP/SN. (2013).

Guia SUNARP. (2016). Superintendencia Nacional de los Registros Públicos. Obtenido de https://www.sunarp.gob.pe/seccion/guia-comunidades/docs/GuiaCampesina-Castellano.pdf 
Ley $\mathrm{N}^{\circ}$ 24656. (1987). art.2.

Ley $N^{\circ}$ 29735. (05 de julio de 2011). Congreso de la República. Diario Oficial EL Peruano. Lima, Perú.

MINISTERIO DE CULTURA. (20 de julio de 2010). Base de datos de pueblos indígenas $u$ originarios. Obtenido de Lista de lenguas indígenas u originarias: https://bdpi. cultura.gob.pe/lenguas

MINISTERIO DE CULTURA. (21 de julio de 2016). Decreto Supremo que aprueba el Reglamento de la Ley N²29735. Decreto Supremo N004-2016-MC. Lima, Lima, Lima.

Pacto Internacional de Derechos Civiles y Políticos. (23 de marzo de 1976). Asamblea General de Naciones Unidas. Nueva York.

Pacto Internacional de Derechos Sociales, Económicos y Culturales. (03 de enero de 1976). Asamblea General de las Naciones Unidas. New York.

Protocolo numero 12 al Convenio para la Protección de los Derechos Humanos y de las Libertades Fundamentales. (25 de enero de 2008). Comite Director de Derechos Humanos.

SORIANO DIAZ, R. L. (2017). Derechos linguisticos y fundamentales. España.

SUPERINTENDENCIA NACIONAL DE LOS REGISTROS PÚBLICOS. (2016). Guía general para la inscripción de actos y derechos de las Comunidades campesinas. Obtenido de https://www.sunarp.gob.pe/seccion/guia-comunidades/docs/GuiaCampesina-Castellano.pdf

VÁSQUEZ MEDINA, J. A. (13 de Noviembre de 2015). XX Congreso Internacional del CLAD sobre la Reforma del Estado y de la Administración Pública. La implementación de derechos lingüísticos para la mejora de servicios públicos y la recuperación y fortalecimiento de lenguas indígenas. Lima. Obtenido de http://www2.congreso. gob.pe/sicr/cendocbib/con4_uibd.nsf/9F0E32B174CBC9A2052580A900735595/\$ FILE/vasqumed.pdf 